\title{
Path Analysis and Curve Estimates of Morphometric Attributes Effects on Body Weight of Two-Month-Old Babylonia areolata
}

\author{
Zhao Wang ${ }^{1,2,3}$, Yang Rui ${ }^{1,2}$, Wu Kaichang ${ }^{1,2}$, Yu Gang ${ }^{1,2}$, Ma Zhenhua ${ }^{1,2}$, Wu Qiaer ${ }^{1,2}$, Huang \\ Yingbang ${ }^{1,2}$, Wen Weigeng ${ }^{1,2^{*}}$ \\ ${ }^{I}$ Tropical Fishery Research and Development Center, South China Sea Fisheries Research Institute, Chinese \\ Academy of Fishery Sciences, Sanya 572018, China \\ ${ }^{2}$ Key Laboratory of South China Sea Fishery Resource Exploitation \& Utilization, Ministry of Agriculture and \\ Rural Affairs, Guangzhou 510300, China \\ ${ }^{3}$ School of Marine Sciences, Ningbo University, Ningbo 315823, China
}

*Corresponding Author: Wen Weigeng, Tropical Fishery Research and Development Center, South China Sea Fisheries Research Institute, Chinese Academy of Fishery Sciences, Sanya 572018, China.

\begin{abstract}
The relationship between morphometric attributes and body weight of Babylonia areolata was analyzed using body weight $(Y)$ and 11 morphometric attributes (X1-X11) from seven-month-old B. areolata. The results show that significant positive correlation between morphometric attributes and body weight, and all the correlation coefficients reach extremely significant level $(P<0.01)$. The path analysis reveal that X2 display the highest positive direct effect (0.373) to body weight, and follow by X7 and X3. X10 affect body weight indirectly by $X 2, X 3$ and $X 7$. The analysis results of determination coefficients show that the total decision coefficient of four morphological attributes to body weight is find to be 0.852, and indicating those morphological attributes are the main factor to body weight. The multiple regression equation is established by multiple regression analysis, the results show that all the best model for two-month-old B. areolata. are including: $Y=0.003 X 22.513, Y=0.003 X 32.435, Y=0.001 X 72.597, Y=-6.496+1.329 X 10$.
\end{abstract}

Keywords: Babylonia areolata; Morphometric attributes; Body weight; Path analysis

\section{INTRODUCTION}

Babylonia areolata (Gastropoda, Stenoglossa, Buccinidae, babylonia) with its delicacy and high economic value, it is one of the most important and popular economic aquatic production in the world. And it is also an important economically farmed shellfish in the southeast coast of China. At present, the cultivation technology of $B$. areolata relatively mature (Kritsanapuntu, 2006; Zheng, 2015). Its nutritional requirements are also relatively clear (Yang, 2013). There have been some reports about physiology biochemistry (Supanopas, 2005; Xue, 2012), diseases (Tanhan, 2005) and artificial breeding (Luo, 2004) of B. areolata. However, studies on parental breeding of B. areolata are still lacking. As a kind of edible shellfish, body weight is usually regarded as one of the breeding indexes, and phenotypic traits are important basis for species classification (Zou, 2014). Through multivariate analysis of the influence of morphological traits on body weight, morphological characteristics can be revealed, and then character screening can be carried out. Therefore, this method has been widely used in aquatic breeding research because of its simple and feasible (Guo, 2013; Liu, 2012; Liu,2002; Liu,2016; Xiao, 2014). Two-month-old B. areolata is in the early stage of development. At this time, selecting the parent with fast growth rate and good morphology of $B$. areolata can reduce the breeding workload and improve the breeding efficiency. So it is instructive to research the relationship between morphometric attributes and body weight of two-month-old $B$. areolata. In this study, the phenotypic character data of 150 two-month-old $B$. areolata were randomly measured. Then the relationship between morphological traits and body weights of two-month-old $B$. areolata were analyzed by multiple regression analysis. In the first place the main influencing traits of body weight were found by correlation analysis and path analysis. Finally, the regression equations of two-month-old B. areolata were established. 
Path Analysis and Curve Estimates of Morphometric Attributes Effects on Body Weight of Two-MonthOld Babylonia areolata

\section{MATERIALS AND METHODS}

\subsection{Materials}

150 two-month-old $B$. areolata with good growth state were randomly collected from a demonstration base of aquacultural farm in wanning, hainan. B. areolata were cultured in ponds covered with black mesh at a density of $1000 / \mathrm{m}^{2}$ (ponds specifications: $300 \times 700 \times 100 \mathrm{~cm}$ ). The bottom of the pond was filled with fine sand with a particle size of $1-3 \mathrm{~mm}$. The daily exchange rate per pound was $200-400 \%$. The salinity was maintained at $27-34 \%$, the rearing temperature was $22-32^{\circ} \mathrm{C}, \mathrm{pH} 7.5-8.3$ and $\mathrm{DO} \geq 5$ $\mathrm{mg} / \mathrm{L}$ throughout the experiment. Feeding rate of Babylonia areolata was 3-10\%, and its food including chilled fish, oyster, shrimp and crab.

\subsection{Measurement Methods}

The body weight $(Y)$ was weighed using an electronic balance which the precision is $0.01 \mathrm{~g}$. The shell height $\left(X_{1}\right)$, shell width $\left(X_{2}\right)$, height of aperture $\left(X_{3}\right)$, width of aperture $\left(X_{4}\right)$, operculum length $\left(X_{5}\right)$, operculum width $\left(X_{6}\right)$, height of body whorl $\left(X_{7}\right)$, height of the second whorl $\left(X_{8}\right)$, height of the third whorl $\left(X_{9}\right)$, width of the second whorl $\left(X_{10}\right)$ and width of the third whorl $\left(X_{11}\right)$ were measured by a digital vernier caliper (Hangzhou) accurate to $0.01 \mathrm{~mm}$.

\subsection{Statistical and Analytical Methods}

Coefficient of variation $(C V)=(\mathrm{SD} / \mathrm{MN}) \times 100 \%(\mathrm{Ming}, 2006)$

Correlation coefficients, path analysis and models curve estimation referred to the methods of $\mathrm{Du}(\mathrm{Du}$, 2010).

Statistical analyses were performed with SPSS 19.0 software (SPSS Inc., Chicago, USA). The descriptive statistical results of each trait were obtained in the first place, and then the direct and indirect effects of morphological traits and the body weight were determined by correlation analysis and path analysis. Finally, multiple regression equation of two-month-old $B$. areolata is established by multiple regression analysis.

\section{RESUltS}

\subsection{The Descriptive Statistic of Morphometric Attributes of Two-Month-Old B. areolata}

The descriptive statistic of morphometric attributes of two-month-old $B$. areolata were showed in Tab.1. The highest $C V$ of all measured traits was $Y(47.62 \%)$, the lowest $C V$ was $X_{9}(14.15 \%)$, and other $C V$ s between $15.72 \%$ and $19.57 \%$. It indicated that the body weight $(Y)$ had a large selection potential in the traits of two-month-old $B$. areolata.

Table1. The descriptive statistic of morphometric attributes of two-month-old B. areolata

\begin{tabular}{|c|c|c|c|c|c|c|}
\hline Attributes & Mean & SD & SE & Kurtosis & Skewness & CV $(\%)$ \\
\hline$Y / \mathrm{g}$ & 0.42 & 0.2 & 0.02 & 0.3 & 0.91 & 47.62 \\
\hline$X_{1} / \mathrm{mm}$ & 13.88 & 2.31 & 0.19 & -0.62 & 0.23 & 16.64 \\
\hline$X_{2} / \mathrm{mm}$ & 8.14 & 1.28 & 0.11 & -0.4 & 0.29 & 15.72 \\
\hline$X_{3} / \mathrm{mm}$ & 7.82 & 1.39 & 0.11 & -0.44 & 0.4 & 17.77 \\
\hline$X_{4} / \mathrm{mm}$ & 4.41 & 0.77 & 0.06 & -0.61 & 0.29 & 17.46 \\
\hline$X_{5} / \mathrm{mm}$ & 3.49 & 0.67 & 0.05 & -0.52 & 0.35 & 19.20 \\
\hline$X_{6} / \mathrm{mm}$ & 6.39 & 1.24 & 0.1 & -0.57 & 0.39 & 19.41 \\
\hline$X_{7} / \mathrm{mm}$ & 10.92 & 1.74 & 0.14 & -0.58 & 0.25 & 15.93 \\
\hline$X_{8} / \mathrm{mm}$ & 1.84 & 0.36 & 0.03 & -0.68 & 0.19 & 19.57 \\
\hline$X_{9} / \mathrm{mm}$ & 1.06 & 0.15 & 0.01 & -0.4 & 0.81 & 14.15 \\
\hline$X_{10} / \mathrm{mm}$ & 3.67 & 0.63 & 0.05 & -0.4 & 0.43 & 17.17 \\
\hline$X_{11} / \mathrm{mm}$ & 2.08 & 0.34 & 0.03 & -0.25 & 0.39 & 16.35 \\
\hline
\end{tabular}

Note: $Y$ is body weight; $X_{1}$ is shell height; $X_{2}$ is shell width; $X_{3}$ is height of aperture; $X_{4}$ is width of aperture; $X_{5}$ is operculum length; $X_{6}$ is operculum width; $X_{7}$ is height of body whorl; $X_{8}$ is height of the second whorl; $X_{9}$ is height of the third whorl; $X_{10}$ is width of the second whorl; $X_{11}$ is width of the third whorl. The codes of the descriptive statistic are universal in the next text. 
Path Analysis and Curve Estimates of Morphometric Attributes Effects on Body Weight of Two-MonthOld Babylonia areolata

\subsection{Correlation Coefficients among Morphometric Attributes of Two-Month-Old B. areolata}

The descriptive statistic of morphometric attributes of two-month-old $B$. areolata were extremely significant, showed in Tab.1. The correlation coefficients of $X_{1}$ and $X_{7}$ was the largest (0.986), however, $X_{5}$ and $X_{8}$ was on the contrary the numerical value was only 0.811 . It also showed that, the largest contribution to body weight of two-month-old $B$. areolata was $X_{2}(0.972)$, but the last was $X_{9}(0.888)$.

Table2. Correlation coefficients among morphometric attributes of two-month-old B. areolata

\begin{tabular}{|c|c|c|c|c|c|c|c|c|c|c|c|}
\hline Attributes & $Y$ & $X_{1}$ & $X_{2}$ & $X_{3}$ & $X_{4}$ & $X_{5}$ & $X_{6}$ & $X_{7}$ & $X_{8}$ & $X_{9}$ & $X_{10}$ \\
\hline$X_{1}$ & $0.968^{* *}$ & & & & & & & & & & \\
\hline$X_{2}$ & $0.972^{* *}$ & $0.975^{* *}$ & & & & & & & & & \\
\hline$X_{3}$ & $0.960^{* *}$ & $0.960^{* *}$ & $0.965^{* *}$ & & & & & & & & \\
\hline$X_{4}$ & $0.929^{* *}$ & $0.934^{* *}$ & $0.938^{* *}$ & $0.962^{* *}$ & & & & & & & \\
\hline$X_{5}$ & $0.917^{* *}$ & $0.917^{* *}$ & $0.914^{* *}$ & $0.909^{* *}$ & $0.891^{* *}$ & & & & & & \\
\hline$X_{6}$ & $0.935^{* *}$ & $0.930^{* *}$ & $0.936^{* *}$ & $0.918^{* *}$ & $0.885^{* *}$ & $0.917^{* *}$ & & & & & \\
\hline$X_{7}$ & $0.969^{* *}$ & $0.986^{* *}$ & $0.979^{* *}$ & $0.967^{* *}$ & $0.935^{* *}$ & $0.924^{* *}$ & $0.942^{* *}$ & & & & \\
\hline$X_{8}$ & $0.889^{* *}$ & $0.918^{* *}$ & $0.884^{* *}$ & $0.874^{* *}$ & $0.852^{* *}$ & $0.811^{* *}$ & $0.836^{* *}$ & $0.896^{* *}$ & & & \\
\hline$X_{9}$ & $0.899^{* *}$ & $0.876^{* *}$ & $0.866^{* *}$ & $0.844^{* *}$ & $0.824^{* *}$ & $0.804^{* *}$ & $0.820^{* *}$ & $0.864^{* *}$ & $0.829^{* *}$ & & \\
\hline$X_{10}$ & $0.955^{* *}$ & $0.966^{* *}$ & $0.953^{* *}$ & $0.947^{* *}$ & $0.920^{* *}$ & $0.904^{* *}$ & $0.905^{* *}$ & $0.957^{* *}$ & $0.906^{* *}$ & $0.853^{* *}$ & \\
\hline$X_{11}$ & $0.888^{* *}$ & $0.908^{* *}$ & $0.897^{* *}$ & $0.884^{* *}$ & $0.854^{* *}$ & $0.828^{* *}$ & $0.823^{* *}$ & $0.892^{* *}$ & $0.841^{* *}$ & $0.815^{* *}$ & $0.921^{* *}$ \\
\hline
\end{tabular}

Note: * represents significant correlation $(\mathrm{P}<0.05)$, ** represents highly significant correlation $(\mathrm{P}<0.01)$.

\subsection{Path Analysis of Morphological Attributes to Body Weight of Two-Month-Old B. areolata}

The path analysis of morphological attributes to body weight of two-month-old B. areolata were showed in Table 3. According to the component effect of correlation coefficient, the relative number of morphological traits and body weight of two-month-old $B$. areolata can be decomposed into two parts: the direct effect of each trait and the indirect effect of each trait through other traits (Guo, 2013). After the significance test, the path coefficient of $X_{2}, X_{9}$ and $X_{10}$ to body weight of two-month-old $B$. areolata were highly significant $(P<0.01), X_{3}$ and $X_{6}$ were significant $(P<0.05)$. It also showed that the path coefficient of $X_{2}$ was maximum in these 5 morphological traits(0.295). In other words, the direct effect of $X_{2}$ on the body weight of two-month-old $B$. areolata was the highest. In terms of indirect effects, the indirect effect of $X_{6}$ on the bod $y$ weight of two-month-old $B$. areolata was larger than other morphological traits $(0.781)$.

Table3. Path analysis of morphological attributes to body weight of two-month-old B. areolata

\begin{tabular}{|c|c|c|c|c|c|c|c|c|}
\hline \multirow{2}{*}{ Attributes } & \multirow{2}{*}{ Correlation coefficient } & \multirow{2}{*}{ Direct } & \multicolumn{5}{|c|}{ Indirect } & \\
\cline { 4 - 9 } & & $\Sigma$ & $X_{2}$ & $X_{3}$ & $X_{6}$ & $X_{9}$ & $X_{10}$ \\
\hline$X_{2}$ & 0.972 & $0.295^{* *}$ & 0.641 & - & 0.187 & 0.109 & 0.164 & 0.181 \\
\hline$X_{3}$ & 0.96 & $0.194^{*}$ & 0.731 & 0.285 & - & 0.106 & 0.160 & 0.180 \\
\hline$X_{6}$ & 0.935 & $0.116^{*}$ & 0.781 & 0.276 & 0.178 & - & 0.155 & 0.172 \\
\hline$X_{9}$ & 0.899 & $0.189^{* *}$ & 0.676 & 0.255 & 0.164 & 0.095 & - & 0.162 \\
\hline$X_{10}$ & 0.955 & $0.19^{* *}$ & 0.731 & 0.281 & 0.184 & 0.105 & 0.161 & - \\
\hline
\end{tabular}

\subsection{Coefficient of Determination of Morphological Attributes to Body Weight of Two-Month-Old B. areolata}

The coefficient of determination of morphological attributes to body weight of two-month-old $B$. areolata were showed in Table 4 . The results showed that the sum of the direct decision coefficient and the indirect decision coefficient was 0.867. It means that $X_{2}, X_{3}, X_{6}, X_{9}$ and $X_{10}$ were the important morphological traits affecting the body weight of two-month-old $B$. areolata, but others just the opposite. The table also demonstrated that there were differences among the impact of these five morphological traits on body weight. $X_{2}$ had the greatest direct determination of body weight for twomonth-old $B$. areolata $(0.087)$, and the less decisive was $X_{6}(0.013)$. The joint action of $X_{2}$ and $X_{3}$ determines the body weight to a maximum of 0.110 , however, $X_{9}$ and $X_{10}$ together determine the least amount of 0.031 . Obviously, the body weight of two-month-old $B$. areolat $a$ is mainly determined by $X_{2}$ and $X_{3}$, next were $X_{6}, X_{9}$ and $X_{10}$. 
Path Analysis and Curve Estimates of Morphometric Attributes Effects on Body Weight of Two-MonthOld Babylonia areolata

Table4. Coefficient of determination of morphological attributes to body weight of two-month-old B. areolate

\begin{tabular}{|c|c|c|c|c|c|c|}
\hline Attributes & $X_{2}$ & $X_{3}$ & $X_{6}$ & $X_{9}$ & $X_{10}$ & $\Sigma \mathrm{d}$ \\
\hline$X_{2}$ & 0.087 & 0.110 & 0.064 & 0.097 & 0.107 & \\
\cline { 1 - 5 } 0 & & 0.038 & 0.041 & 0.062 & 0.070 & \multirow{2}{*}{0.867} \\
\hline$X_{3}$ & & & 0.013 & 0.036 & 0.040 & \\
\hline$X_{9}$ & & & & 0.036 & 0.031 & \\
\hline$X_{10}$ & & & & & 0.036 & \\
\hline
\end{tabular}

\subsection{Establishment of Multiple Regression Equations}

Through multiple regression analysis, the morphological traits with insignificant partial regression coefficients were eliminated. The multiple regression equations of morphological traits and body weight of two-month-old $B$. areolata were established by using the significant partial regression coefficients:

$Y=-0.856+0.049 X_{2}+0.028 X_{3}+0.023 X_{6}+0.263 X_{9}+0.064 X_{10}$

In the equation, $Y$ is body weight, $X_{2}$ is shell width, $X_{3}$ is height of aperture, $X_{6}$ is operculum width, $X_{9}$ is height of the third whorl, $X_{10}$ is width of the second whorl.

Analysis of variance displayed, the regression relationship of multiple regression equations is extremely significant $(F=937.134, P=0.000<0.01), R^{2}=0.969$. After the significance test, the partial regression coefficient of the regression equation showed that the partial regression coefficient of these 5 morphological traits $\left(X_{2}, X_{3}, X_{6}, X_{9}\right.$ and $X_{10)}$ to body weight of two-month-old $B$. areolata reached the significant or extremely significant level $\left(X_{2}: t=4.394, P=0.000<0.01 ; X_{3}: t=3.192, P=0.002<0.01 ; X_{6}\right.$ : $\left.t=3.414, P=0.001<0.01 ; X_{9}: t=6.415, P=0.000<0.01 ; X_{10}: t=3.873, P=0.000<0.01\right)$.

\subsection{Models Curve Estimation Results of Two-Month-Old B. areolata}

The curve model was estimated by using $X_{2}, X_{3}, X_{6}, X_{9}$ and $X_{10}$ as independent variables and $Y$ as dependent variables (Tab.5). It showed that the optimal fitting models of $X_{2}, X_{3}, X_{6}, X_{9}$ and $X_{10}$ and body weight of two-month-old $B$. areolata were quadratic function, quadratic function, quadratic function, quadratic function and power function respectively. The regression equations were separately: $Y=-$ $0.145 X_{2}^{2}+0.018 \quad X_{2}+0.377, \quad Y=-0.05 X_{3}^{2}+0.012 \quad X_{3}+0.068, \quad Y=-0.052 X_{6}^{2}+0.016 \quad X_{6}+0.094, \quad Y=-$ $0.519 X_{9}{ }^{2}+0.792 X_{9}+0.063, Y=0.011 X_{10}^{2.734}$, and the $R^{2}$ were $0.977,0.938,0.891,0.814$, and 0.928 , respectively.

Table5. Models curve estimation results of two-month-old B. areolata

\begin{tabular}{|c|c|c|c|c|c|c|c|}
\hline \multirow{2}{*}{ regression } & \multirow{2}{*}{ model } & \multicolumn{3}{|c|}{ model summary } & \multicolumn{3}{|c|}{ parameter estimate } \\
\hline & & $R^{2}$ & $F$ & $P$ & constant & $b 1$ & $b 2$ \\
\hline \multirow{5}{*}{$X_{2}-Y$} & linear & 0.946 & 2562.795 & 0 & -0.841 & 0.155 & \\
\hline & logarithmic & 0.905 & 1398.735 & 0 & -2.144 & 1.23 & \\
\hline & quadratic function & 0.977 & 3110.377 & 0 & 0.377 & -0.145 & 0.018 \\
\hline & power & 0.966 & 4145.321 & 0 & 0.001 & 3.029 & \\
\hline & exponential & 0.96 & 3511.822 & 0 & 0.018 & 0.372 & \\
\hline \multirow{5}{*}{$X_{3}-Y$} & linear & 0.921 & 1721.077 & 0 & -0.679 & 0.141 & \\
\hline & logarithmic & 0.887 & 1162.473 & 0 & -1.795 & 1.085 & \\
\hline & quadratic function & 0.938 & 1108.83 & 0 & 0.068 & -0.05 & 0.012 \\
\hline & power & 0.937 & 2183.641 & 0 & 0.002 & 2.66 & \\
\hline & exponential & 0.923 & 1764.514 & 0 & 0.027 & 0.336 & \\
\hline \multirow{5}{*}{$X_{6}-Y$} & linear & 0.874 & 1030.986 & 0 & -0.565 & 0.154 & \\
\hline & logarithmic & 0.84 & 779.065 & 0 & -1.361 & 0.97 & \\
\hline & quadratic function & 0.891 & 603.494 & 0 & 0.094 & -0.052 & 0.016 \\
\hline & power & 0.886 & 1155.032 & 0 & 0.005 & 2.376 & \\
\hline & exponential & 0.875 & 1034.062 & 0 & 0.036 & 0.368 & \\
\hline \multirow{5}{*}{$X_{9}-Y$} & linear & 0.807 & 620.445 & 0 & -0.909 & 1.253 & \\
\hline & logarithmic & 0.796 & 576.131 & 0 & 0.351 & 1.372 & \\
\hline & quadratic function & 0.814 & 321.234 & 0 & 0.063 & -0.519 & 0.792 \\
\hline & power & 0.744 & 430.925 & 0 & 0.32 & 3.165 & \\
\hline & exponential & 0.733 & 406.062 & 0 & 0.018 & 2.846 & \\
\hline \multirow{2}{*}{$X_{10}-Y$} & linear & 0.912 & 1534.129 & 0 & -0.707 & 0.307 & \\
\hline & logarithmic & 0.882 & 1109.793 & 0 & -1.016 & 1.118 & \\
\hline
\end{tabular}


Path Analysis and Curve Estimates of Morphometric Attributes Effects on Body Weight of Two-MonthOld Babylonia areolata

\begin{tabular}{|c|c|c|c|c|c|c|c|}
\hline \multirow{2}{*}{} & quadratic function & 0.924 & 895.946 & 0 & -0.038 & -0.055 & 0.048 \\
\cline { 2 - 8 } & power & 0.928 & 1898.241 & 0 & 0.011 & 2.734 & \\
\cline { 2 - 8 } & exponential & 0.912 & 1537.674 & 0 & 0.025 & 0.733 & \\
\hline
\end{tabular}

\section{DISCUSSION AND CONCLUSION}

As a kind of edible economic shellfish, the body weight of $B$. areolata is directly related to the yield and culture cycle. Morphological traits are closely related to body weight, and the main morphological traits affecting body weight can be determined by path analysis. The correlation between independent variables and dependent variables can be decomposed into direct and indirect effects of independent variables (morphological traits) on dependent variables (body weight) by path analysis (Yan, 2010). In this study, the correlation coefficient between various morphological traits and body weight was extremely significant, ranging from 0.811 to 0.986 . The result of path analysis showed that the direct effect of five morphological traits on body weight were significant or extremely significant, and these morphological traits including shell width, height of aperture, operculum width, height of the third whorl and width of the second whorl. The direct impact of operculum width on body weight was minimal, but it had a great indirect effect on the body weight through the other four morphological traits. However, shell width had the greatest direct effect on body weight, and the indirect effect of shell width on body weight through other morphological traits was negligibly small oppositely. Therefore, the influence of various morphological traits on body weight cannot be correctly determined by the phenotypic correlation coefficient between various traits, while path analysis can further find out the main morphological traits affecting body weight on the basis of phenotypic correlation analysis. The research results were consistent with the actual production.

The results of shellfish path analysis showed that different snails had different morphological traits that affect their body weight. Shell width was the main traits that affected the body weight of two-year-old Neverita didyma (Sun, 2010). Qin (2014) found that shell width was the main morphological trait that determines the body weight of Babylonia lutosa. The body weight of Pomacea canaliculata is mainly determined by shell width, shell height and shell mouth width (Li, 2012). There were also differences in the traits affecting the body weight of other bivalve shellfish. Such as shell height, shell width, hinge line length and shell length are the main characters that determine the body mass of wild Amusium pleuronectes(Wang, 2009). Outer ligament length, and shell width were the key effective factors, bearing predominant, direct effect and determinacy on the live body weight of Meretrix lyrata (Liu, 2011). Shell height, shell width and shell length were the most important traits for breeding of Pinctada margaritifera (Yan, 2015). The morphological characters that affect the weight of shellfish may also be different at different growth stages. The effect of morphometric traits on body weight of Scapharca subcrenata Lischke was different at different ages. The shell length had major effects on the body weight at one-year-old, the shell length and shell width had major effects on the body weight at two years old, the shell width had major effects on the body weight at three years old (Li, 2015). Liu et al. (2012) analyzed four quantitative traits (shell height, shell length, shell width, and body) of the luxurious lamina scallops (Chlamys nobilis) at the ages of 3 months, 6 months, 7 months, 9 months, and 15 months, and the results show that the shell width has the smallest path coefficient to body mass. Except for 7 months of age, the shell height to body mass has a larger path coefficient than shell length. From what has been discussed above, the breeding characters of different stages were different. This study believes that the selection of shell width, shell height, shell mouth height, secondary shell width and other morphological characters should be strengthened in the selection of two-month-old $B$. areolata.

\section{ACKNOWLEDGMENT}

This research was financially supported by Hainan Provincial Natural Science Foundation of China (318QN304); Special Funds for the Construction of Modern Agricultural Industry Technology System(CARS-49); Project of Academy Locality Science and Technology Cooperation of Sanya (2018YD19, 2019YD21).

\section{REFERENCES}

[1] Du J, Chen Z, Liu X, et al. The method of path analysis is implemented by using SPSS linear regression[J]. Bulletin of Biology, 2010, 45(2): 4-6. 
[2] Guo H, Chen M, Wang Y, et al. Correlation and path analysis of main economic traits of wild population of Trachycardium flavum [J]. South China Fisheries Science, 2013, 9(2): 1-8.

[3] Kritsanapuntu S, Chaitanawisuti N, Santhaweesuk W, et al. Effects of water exchange regimes on growth, survival and shell normality of the hatchery reared juvenile spotted babylon (Babylonia areolata Link 1807) in a recirculating seawater system[J]. Aquaculture International, 2006, 14(6): 587-594.

[4] Li L, Zheng Y, Xu K, et al. The relationship between morphometric traits and body weight of Scapharca subcrenata at different ages[J]. Marine Sciences, 2015, 39(6): 54-58.

[5] Li X, Xu M, Luo D, et al. Correlation analysis of morphometric traits and body mass of the golden apple snail Pomacea canaliculata in Guangdong province, China[J]. Journal of Biosafety, 2012, 21(4): 283-286.

[6] Lin X, Chang Y, Xiang J, et al. Mathematical analysis of effects of morphometric attributes on body weight for Penaeus vannamei [J]. Acta Ecologica Sinica, 2002, 33(6): 673-678.

[7] Liu B, Teng S, Shao Y, et al. Mathematical analysis of the correlations between the morphometric attributes and body weight Meretrix.lyrata [J]. Marine Sciences, 2011, 35(10): 91-95.

[8] Liu W, Lin J, He M. Path analysis of quantitative traits of scallop Chlamys nobilis at different ages[J]. South China Fisheries Science, 2012, 8(1): 43-48.

[9] Liu Y, Liu Y, Liu Y, et al. Correlation between morphological traits and body weight of Japanese flounder during different periods[J]. Hubei Agricultural Sciences, 2016, 12(1): 36-42.

[10] Luo J, Du T, Liu C, et al. The influence of $\mathrm{pH}$ and salinity in hatching rate of egg sac of Babylonia areolate and the effect of different diet on the development, survival rate of the larvae [J]. Marine Sciences, 2004, 28(6): 5-9.

[11] Ming D. Advanced biometrics[M]. BeiJing: China Agriculture Press, 2006.

[12] Qin Q. Study on the genetic diversity and morphology of Babylonia lutosa[D]. Agricultural University of Hunan, 2014.

[13] Sun Z, Chen L, Xu J, et al. Effetc of phenotypic morphometric traits on body weight and soft-tissue weight of Neverita didyma [J]. Oceanologia et Limnologia Sinica, 2010, 41(4): 513-518.

[14] Supanopas P, Sretarugsa P, Kruatrachue M, et al. Acute and subchronic toxicity of lead to the spotted Babylon, Buabylonia areolata (Neogastropoda, Buccinidae)[J]. Journal of Shellfish Research, 2005, 24(1): 91-98.

[15] Tanhan P, Sretarugsa P, Pokethitiyook P, et al. Histopathological alterations in the edible snail, Babylonia areolata (spotted babylon), in acute and subchronic cadmium poisoning[J]. Environmental Toxicology, 2005, 20(2): 142-149.

[16] Wang Y, Ye L, Chen X, et al. Path analysis on the morphological and weight characters of wild Amusium pleuronectes in Hainan[J]. Journal of Anhui Agricultural Sciences, 2009, 37(8): 3570-3572.

[17] Xue M, Ke C. Cadmium bioaccumulation and its toxicity in Babylonia areolata under different nutritional status[J]. Chinese Journal of Applied Ecology, 2012, 23(7): 1965-1972.

[18] Yan F, Wang Z, Liu X, et al. Path analysis of the effects of morphometric traits on body weight for 3-month aged Paralichthys olivaceus[J]. Progress in Fishery Sciences, 2010, 31(2): 45-50.

[19] Yan J , Liu B, Li Y, et al. Effects of phenotypic traits on body weight in wild population of pearl oyster Pinctada margaritifera[J]. Fisheries Scinence, 2015, 34(9): 560-564.

[20] Yang Y, Wu Y, Dong X, et al. Dietary zinc requirement of spotted babylon, Babylonia areolate [J]. Chinese Journal of Animal Nutrition, 2013, 25(3): 643-650.

[21] Zhen J, Gao X, Qiu T, et al. Effect of different bottom substrate materials on the growth and survival of spotted babylon (Babylonia areolata) [J]. Marine Sciences, 2015, 39(11): 1-6.

[22] Zou L, Fu Y, Wang Z, et al. The Study of the effect of phenotypic and morphometric traits on body weight of Mytilus edulis Linnaeu of various regions in the stage of growth turning [J]. Journal of Zhejiang Ocean University (Natural Science), 2014, 33(3): 244-250.

Citation: Wen Weigeng, et.al, "Path Analysis and Curve Estimates of Morphometric Attributes Effects on Body Weight of Two-Month-Old Babylonia areolata”. International Journal of Innovative Studies in Aquatic Biology and Fisheries, 6(1), pp.29-34. http://dx.doi.org/10.20431/2454-7670.0601004

Copyright: (C) 2020 Authors. This is an open-access article distributed under the terms of the Creative Commons Attribution License, which permits unrestricted use, distribution, and reproduction in any medium, provided the original author and source are credited. 